\title{
Betre oppfølging av diabetes på sjukeheimar aukar livskvaliteten
}

Fleire eldre får diabetes. Klinisk audit på sjukeheimar kan vere ein god metode for å sikre kunnskapsbasert behandling og oppfølging.

\section{Forfattere}

\section{Laila Nordheim Alme}

Fagutviklingssykepleier

Ladegården sykehjem

\section{Anne Haugstvedt}

Førsteamanuensis

Høgskulen på Vestlandet

\section{Nøkkelord}

Kvalitet Ledelse Geriatri Diabetes

Sykepleien 2018 106(65390)(e-65390)

DOI: https://doi.org/10.4220/Sykepleiens.2018.65390

\section{HOVEDBUDSKAP}

Diabetes er vanleg i sjukeheimar. Studiar har vist at diabetesoppfølginga ofte ikkje samsvarar med tilrådingar i kunnskapsbaserte retningsliner. Dette var utgangspunktet for eit kvalitetsprosjekt på to sjukeheimspostar ved Ladegården sykehjem i Bergen kommune. Små, men viktige justeringar førte til at praksis blei kunnskapsbasert, og at pasienttryggleiken blei betre. Klinisk audit kan vere ein god metode i kvalitetsarbeidet. 
Diabetes er ei følgje av utilstrekkeleg eller manglande insulinproduksjon eller nedsett blodsukkersenkande effekt av insulinet (insulinresistens). God kontroll med blodsukkeret er vesentleg for livskvaliteten til menneske med diabetes. Hos yngre med diabetes er hovudmålet oftast å førebyggje

langtidskomplikasjonar. For dei eldste med diabetes er hovudmålet å unngå symptomgjevande høge og låge blodsukkerverdiar (1).

Symptoma hos eldre kan ofte vere atypiske og kan lett bli mistolka som generelle aldringssymptom. Ved tilleggssjukdomar og kognitiv svikt kan det vere ekstra utfordrande å tolke symptoma. Kunnskapsbaserte behandlingsretningsliner understrekar behovet for individuell oppfølging og behandling også av dei eldste med diabetes $(1,2)$.

\section{इ «Det er behov for eit systematisk kvalitetsarbeid ved sjukeheimar.»}

Ein norsk studie frå 19 sjukeheimar i Helse Vest sitt geografiske område, viste ein gjennomsnittleg førekomst av diabetes på 16 prosent (3). Det er venta at omfanget vil stige fordi fleire enn tidlegare får diabetes, og fordi fleire blir eldre. Det er viktig at sjukeheimar er førebudde på dei behandlings- og oppfølgingsoppgåvene som diabetes medfører. Jamvel om diabetes sjeldan er hovuddiagnose ved innlegging (1), er det viktig at sjukeheimane har gode rutinar for oppfølging og behandling.

\section{Bakgrunn}


Hausten 2011 blei det ved tre sjukeheimar i Bergen

gjennomført ein studie, «Dokumentasjon og

oppfølging av bebuarar med diabetes i sjukeheim» (4).

Studien viste eit stort sprik mellom praksis for

oppfølging av pasientane sine blodsukkernivå og dei

kunnskapsbaserte tilrådingane om diabetesoppfølging

(1). Hos om lag 25 prosent av deltakarane var ikkje

diabetesdiagnosen dokumentert i elektronisk

pasientjournal (EPJ). Dei fleste mangla også

individuelt behandlingsmål for HbA1c og rutinar for

oppfølging av blodsukkeret. HbA1c er eit viktig mål

for blodsukkerreguleringa hos personar med diabetes.

\section{KLINISK AUDIT}

Ein klinisk audit evaluerer i kva grad helsetenestene møter kunnskapsbaserte tilrådingar og har som mål å betre helsetilbodet til pasienten.

National Institute for Clinical Excellence, Storbritannia, definerer klinisk audit som ein «kvalitetssøkande prosess med hensikt å betre pasientbehandling gjennom systematisk gjennomgang av behandlinga mot bestemte kriterium, samt implementering av endringar» (14).

Studien konkluderte med at det er behov for eit systematisk kvalitetsarbeid ved sjukeheimar, og ein såkalla klinisk audit er ein tilrådd metode. Hausten 2015 starta eit samarbeid mellom Høgskulen i Bergen (no: Høgskulen på Vestlandet) og leiinga ved to sjukeheimar i Bergen kommune. Målet var å implementere tilrådingar frå fagprosedyren «Diabetes i sykehjem» (1). Ladegården sykehjem var ein av sjukeheimane.

\section{Oppstart}

Ladegården sykehjem har 107 plassar delt på fem postar, fire for langtidsbebuarar og ein for korttids- og rehabiliteringspasientar. Fagbemanninga er god. Då prosjektarbeidet starta, hadde 16 bebuarar (om lag 15 prosent) diagnosen diabetes. 
To postar blei valde til å delta i prosjektet. Post A er ein korttids- og rehabiliteringspost med 26 pasientar, post $\mathrm{B}$ er ein langtidspost med 17 bebuarar.

Sjukepleiarane og helsefagarbeidarane ved dei to deltakande postane fekk til saman to timar undervising om kunnskapsbasert praksis og innhaldet $\mathrm{i}$ fagprosedyren «Diabetes i sykehjem». Ved kvar av dei to postane blei det deretter oppretta ei arbeidsgruppe som skulle utføre det interne kvalitetsarbeidet med utgangspunkt i metoden klinisk audit.

\section{Evaluering av praksis}

Klinisk audit er ein metode for å evaluere om praksis er i samsvar med kunnskapsbaserte retningsliner, etterfølgd av tiltak i dei tilfella praksis ikkje er i samsvar med tilrådingane (5-9). Målet er å auke kvaliteten på pasientbehandlinga, betre behandlingsresultatet, forenkle prosedyrar og betre ressursbruken (6). Ein klinisk audit er ein syklisk prosess med fleire trinn $(5,9)$.

Figur 1: Klinisk audit-sirkelen $(5,9)$

5. Iverksett tiltak og gjer ny kartlegging
2. Sett kriterium

og standard
4. Samanlikn praksis mot kriterium og standard
3. Kartlegg praksis
1. Identifiser forbetringsområde 
Trinn 1 i audit-sirkelen identifiserer eit område der ein vil vurdere om praksis er i samsvar med gjevne tilrådingar. Trinn 2 definerer målbare kriterium for kunnskapsbasert og tilrådd praksis og ein standard for kva som er realistisk måloppnåing $(5,8,9)$.

Trinn 3 måler praksis slik han er i dag på grunnlag av til dømes data frå journalar eller spørjeskjema til pasientar og helsepersonell. Det er viktig med ein god og detaljert plan for datainnsamlinga (9). Trinn 4 samanliknar praksis med kriteria og standardane. Dersom evalueringa viser at praksis ikkje er som tilrådd, går ein vidare til trinn 5 i audit-sirkelen, som er val og iverksetjing av tiltak.

Når ein skal implementere ny, varig praksis, er det viktig med verksame tiltak og gode strategiar for tilbakemelding til dei involverte $(7,8)$. Etter ei tid bør det bli gjennomført ein ny audit (re-audit) for å undersøke om tiltaka har ført til endra praksis. Ein reaudit kan bli gjort fleire gongar for å sikre at den endra praksisen er varig. Forankring i leiinga og nok tid til gjennomføring er avgjerande for å lukkast med ein klinisk audit (6).

\section{Kvalitetsarbeidet}

Ei arbeidsgruppe med to sjukepleiarar og to helsefagarbeidarar blei oppretta ved kvar av dei deltakande postane på Ladegården sykehjem. Gruppene samarbeidde med sjukeheimslege og fekk rettleiing frå Høgskulen i Bergen. I det følgjande vil vi gjere greie for arbeidet, trinn for trinn.

Trinn 1: Innsatsområda blei drøfta på postane. Det var naturleg å ta utgangspunkt i studien frå 2011 (4). Ladegården var ein av sjukeheimane som deltok i denne studien. Oppfølging av blodsukkeret til personar med diabetes var sentralt i studien. Det vil seie at diagnosen er registrert, at behandlingsmål og rutinar for måling av blodsukker er individualisert og dokumentert, og at blodsukkerreguleringa og risikoen for hypoglykemi er under kontroll. 
Begge postane valde desse elementa for sin kliniske audit. Det er viktig at diagnosen diabetes (inkludert type) er kjend for alle som arbeider med desse bebuarane. Studien frå dei 19 sjukeheimane i Helse Vest sitt geografiske område (3) viste at 60 prosent av bebuarane med diabetes hadde hatt blodsukkerverdiar under $4 \mathrm{mmol} / \mathrm{l}$ på dagtid eller under $6 \mathrm{mmol} / \mathrm{l}$ fastande i løpet av ein fire vekers periode.

\section{三 «Oppfølging av blodsukkeret til personar med diabetes var sentralt i studien.»}

Både individuelle mål og rutinar kan vere med på å førebyggje låge blodsukkerverdier. Studien konluderte med at mange av bebuarane ved sjukeheimane var overbehandla. Det kan vere eit resultat av dårlege eller mangelfulle rutinar for oppfølging av blodsukkeret og påfølgjande justeringar av dei blodsukkersenkande medikamenta.

Systematisk kartlegging av risikoen for hypoglykemi kan førebyggje lågt blodsukker. Kartlegging vil også kunne gjere helsepersonell merksame på einskildpasientar der medikament og tilleggssjukdomar gir auka risiko for lågt blodsukker.

Trinn 2: Dei to postane definerte høvesvis fire og fem kriterium for god praksis ved oppfølging av pasientenes blodsukker. For kvart kriterium blei det definert ein standard. Standarden for måloppnåing blei sett til 100 prosent for alle kriteria (sjå tabell 1). 


$\begin{array}{lc}\text { Kriterium* } & \text { Standard } \\ \begin{array}{l}\text { 1. Hos alle pasientar/bebuarar med diabetes er diagnosen (inkludert type) } \\ \text { tilgjengeleg i elektronisk pasientjournal (EPJ) og kardex. }\end{array} & 100 \% \\ \begin{array}{l}\text { 2. Hos alle pasientar/bebuarar med diabetes er individuelle behandlingsmål } \\ \text { for HbA1c definerte i EPJ og kardex. }\end{array} & 100 \% \\ \begin{array}{l}\text { 3. Hos alle pasientar/bebuarar med diabetes blir HbAlc målt minimum kvar } \\ \text { sjette månad etter individuell vurdering. Resultat er tilgjengeleg i EPJ og kardex. }\end{array} & 100 \% \\ \begin{array}{l}\text { 4. Hos alle pasientar/bebuarar med diabetes er individuell rutine for } \\ \text { blodsukkermålingar dokumentert i EPJ og kardex. }\end{array} & 100 \% \\ \text { 5. Alle pasientar med diabetes får kartlagt risiko for hypoglykemi kvar } \\ \text { sjette månad. Resultatet er tilgjengeleg i EPJ og kardex (berre post B). }\end{array}$

Trinn 3: Med utgangspunkt i kriteria blei praksis kartlagt på grunnlag av dokumentasjon i EPJ og kardex. Eit eige datainnsamlingsverktøy blei utvikla for datainnsamlinga. Pasientjournalen ved sjukeheimen er delt i ein elektronisk pasientjournal (EPJ) og ein papirjournal. Kardex er ein del av papirjournalen. Ved gjennomføringa av klinisk audit var det to pasientar med diabetes på post $\mathrm{A}$ og fire bebuarar med diabetes på post $\mathrm{B}$.

Trinn 4: Kartlegginga, med utgangspunkt i dei valde kriteria, viste at alle bebuarane med diabetes hadde diagnosen dokumentert i EPJ, men ikkje i kardex. Ingen av dei fire bebuarane med diabetes på post $\mathrm{B}$ hadde individuelle behandlingsmål for blodsukkerreguleringa. På post A blei behandlingsmål identifiserte i EPJ, men dei var ikkje tydelege.

Behandlingsmåla var ikkje dokumenterte i kardex.

Individuelle rutinar for blodsukkermåling var dokumentert i EPJ for dei to pasientane på post A, medan det berre var dokumentert $\mathrm{i}$ kardex for dei fire bebuarane på post $\mathrm{B}$. Hos alle var dokumenterte HbA1c-verdiar tilgjengelege i EPJ.

\section{三 «Behandlingsmåla var ikkje dokumenterte i kardex.»}


Trinn 5: Kartlegginga viste at oppfølginga av

blodsukkeret til bebuarane med diabetes kan bli betre.

Relevante behandlingsmål, tiltak og rutinar blei diskuterte med pleiepersonalet på postane og med sjukeheimslegen. Leiinga på postane var involvert.

For å sikre god kvalitet og at alle veit kven som har diabetes, blei «Glukosemålingsskjema - 24 timer» $\mathrm{i}$ EPJ teke i bruk. Både diagnose, type diabetes, behandlingsmål, siste målte HbA1c-verdi, rutinar for blodsukkermåling og målte blodsukkerverdiar blei førte inn. Kopi av skjemaet ligg i kardex på begge postane.

I samråd med sjukeheimslegen blei det på post B (langtidsposten) avtalt halvårlege målingar av HbA1c av alle bebuarar med diabetes, i samband med legemiddelgjennomgangen (11) på posten. Post A (korttidsposten) gjennomfører målingane ved innkomst. Post B innførte også halvårleg kartlegging av risiko for hypoglykemi hos bebuarar med diabetes.

\section{三 «Post B innførte halvårleg kartlegging av risiko for hypoglykemi hos bebuarar med diabetes.»}

Det blei nytta ein norsk versjon av Hypoglycemia Risk Assessment Tool, som er utvikla i Australia og tilrådd i dei australske retningslinene for diabetes i sjukeheimar (10). Alle tilsette blei informerte om dei nye rutinane.

Ein re-audit, som blei gjennomført om lag eit halvår seinare, viste at oppfølginga av bebuarar med diabetes var i samsvar med kriteria. Oppdatert dokumentasjon var tilgjengeleg både i EPJ og kardex, og dei tilsette rapporterte om betra pasienttryggleik i oppfølginga av bebuarar med diabetes.

\section{Drøfting}


Gjennomføringa av klinisk audit, som inkluderte ti bebuarar med diabetes, viste klar betring på fleire område, samanlikna med funna i Heimro sin studie frå 2011 (4). Ved tidspunktet for re-audit var diagnosen dokumentert $\mathrm{i}$ alle pasientjournalane til bebuarane med diabetes.

Det er dokumentert at alle har fått målt HbA1c i løpet av dei siste seks månadane, og at alle har individuelle rutinar for blodsukkermåling. Vi trur at deltaking i studien frå 2011 har gitt generell læring, og at dei tilsette er blitt betre kjende med fagprosedyren «Diabetes i sykehjem». Post A og B har stabilt personale med kompetente sjukepleiarar og helsefagarbeidarar, og leiinga legg stor vekt på at bemanninga alltid er forsvarleg. Legetenesta er blitt vesentleg styrka dei siste fire åra. Halvårleg legemiddelgjennomgang (11) blir gjennomført hos alle bebuarane på langtidspostar.

På sikt vil pasientjournalen bli fullelektronisk. Av praktiske omsyn må førebels nokre av dokumenta i pasientjournalen vere tilgjengelege både i EPJ og i papirversjonen.

Kardex er ein del av papirversjonen. Dokumentasjonen av gjevne legemiddel ligg berre i kardex. Forskrift om pasientjournal (12) seier at pasientjournalen kan ha fleire deler, og at dette skal vere opplyst i det som er definert som hovudjournalen. Forskrifta seier vidare at relevant og nødvendig informasjon skal vere tilgjengeleg for dei som treng det, og at pasientjournalen skal vere oppdatert. Journalen skal lagrast utilgjengeleg for uvedkomande. Kardex skal vere nedlåst i separat hylle i legemiddelvogna når han ikkje er i bruk.

\section{三 «Leiing, betre kvalitet og pasienttryggleik er stikkord i den nye kvalitetsforskrifta.»}


Leiing, betre kvalitet og pasienttryggleik er stikkord i den nye kvalitetsforskrifta frå 1. januar 2017 (13).

Leiinga si rolle i alle ledd av tenesteytinga er grundig omtala. Det gjeld plikta til planlegging og

gjennomføring av helsetenester og plikta til å evaluere og korrigere.

Klinisk audit blei for oss ein god metode for eigenkontroll. Mellom anna fann vi at to postar, i kvar sin etasje i den same sjukeheimen, hadde ulik praksis for oppfølgig av diabetespasientar. På post A hadde pasientane behandlingsmål for HbA1c, på post $\mathrm{B}$ hadde dei det ikkje.

I gjennomføringa av prosjektet såg vi at det er behov for å samordne diabetesinformasjonen i EPJ. Det er difor utarbeidd forslag til eit nytt elektronisk skjema der all dokumentasjon om diabetes er samla på ein stad. Skjemaet skal også ligge i kardex.

\section{Konklusjon}

Klinisk audit er ein enkel, strukturert og lett forståeleg metode. Leiarar i helsetenesta kan bruke metoden til eigenkontroll når dei vil finne ut om det er samsvar mellom kunnskapsbaserte tilrådingar og praksis på ulike område. Gjennomføring av klinisk audit vil vere overkomeleg for dei fleste postar i ein sjukeheim. Vårt kvalitetsforbedringsprosjekt om blodsukkerregulering til pasientar og bebuarar med diabetes i sjukeheim viste at viktige og lite ressurskrevjande justeringar kan føre til ein meir kunnskapsbasert praksis og betre pasienttryggleik.

\section{Referansar}

1. Hølleland G, Sunnevåg K. Diabetes i

sykehjem. Bergen kommune og Utviklingssenter for sykehjem og hjemmetjenester i Hordaland:

Helsebiblioteket.no/Fagprosedyrer; 2011. Tilgjengeleg frå:

http://www.helsebiblioteket.no/fagprosedyrer/ferdige/diabetesi-sykehjem-behandling (nedlasta 30.01.2018). 
2. International Diabetes Federation (IDF). IDF

global guideline for managing older people with type 2 diabetes. IDF; 2013. Tilgjengeleg frå:

https://www.idf.org/e-library/guidelines/78-globalguideline-for-managing-older-people-with-type-2diabetes.html (nedlasta 30.01.2018).

3. Andreassen LM, Sandberg S, Kristensen GBB, Sølvik UØ, Kjome RLS. Nursing home patients with diabetes: prevalence, drug treatment and glycemic control. Diabetes Research and Clinical Practice. 2014;105(1):102-9.

4. Heimro LS, Haugstvedt A. Dokumentasjon og oppfølging av bebuarar med diabetes i sjukeheim. Sykepleien Forskning. 2015;10(3):216-26.

Tilgjengeleg frå:

https://sykepleien.no/forskning/2015/08/dokumentasjonog-oppfolging-av-bebuarar-med-diabetes-i-sjukeheim (nedlasta 23.01.2018).

5. Nortvedt MW, Jamtvedt G, Graverholt B, Nordheim LV, Reinar LM. Jobb kunnskapsbasert! En arbeidsbok. 2. utg. Oslo: Akribe; 2012.

6. Burgess R. How to use this book. I: Burgess $\mathrm{R}$, red. NEW principles of best practice in clinical audit. 2. utg. London: Radcliffe Publishing; 2011. s. x$\mathrm{xV}$.

7. Borbasi S, Jackson D, Lockwood C. Undertaking a clinical audit. I: Courtney M, McCutcheon H, red. Using evidence to guide nursing practice. 2. utg. Chatswood: Elsevier Australia; 2010. s. $113-31$.

8. Benjamin A. Audit: How to do it in practice. British Medical Journal. 2008;336:1241-5.

9. National Institute for Clinical Exellence. Principles for best Practice in Clinical Audit. Oxon: Radcliff Medical Press. 2002. 
10. Dunning T, Duggan N, Svage BA. The McKellar guidelines for managing older people with diabetes in residential and other care setting. Geelong: Centre for Nursing and Allied Health, Deakin University and Barwon Health; 2014.

11. Bergen kommune, Etat for alders- og sykehjem. Prosedyre for legemiddelgjennomgang og samstemming av legemiddellisten for pasienter med langtidsopphold i sykehjem. Ufravikelig prosedyre, gyldig til 15.03.2018. 2013.

12. Forskrift 21. desember 2000 om pasientjournal. Tilgengeleg frå:

https://lovdata.no/dokument/SF/forskrift/2000-12-211385 (nedlasta 16.01.2018).

13. Forskrift 28. oktober 2016 om ledelse og kvalitetsforbedring i helsetjenesten. Tilgjengeleg frå: https://lovdata.no/dokument/LTI/forskrift/2016-10-28$\underline{1250}$ (nedlasta 16.01.2018).

14. Bergene EH. Klinisk audit (clinical audit) som arbeidsmetode mot riktig legemiddelbruk [internett]. Oslo: Norsk Farmaceutisk Tidsskrift; 21.01.2008 [sitert 31.01.2017]. Tilgjengeleg frå: https://www.farmatid.no/artikler/fag/klinisk-auditclinical-audit-som-arbeidsmetode-mot-riktiglegemiddelbruk 